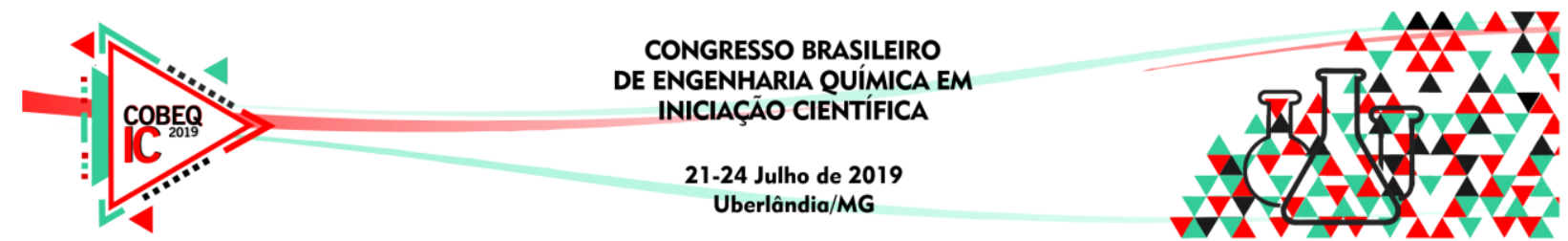

\title{
SÍNTESE E APLICAÇÃO DE POLIANILINA DOPADA COM NÍQUEL METÁLICO INSERIDA EM TINTA A OLÉO PARA PROTEÇÃO ANTICORROSIVA
}

\author{
G.G. SILVA ${ }^{1}$, L. M. MELO ${ }^{1}$, N. S. OLIVEIRA ${ }^{1}$ e S. L. Nogueira ${ }^{1}$ \\ ${ }^{1}$ Centro Universitário de Patos de Minas, Faculdade de Engenharia Química \\ E-mail para contato: lorranamagalhaesmelo@gmail.com
}

\begin{abstract}
RESUMO - O uso de polímeros condutores, como a polianilina (Pani-ES) utilizada neste trabalho, está cada vez mais sendo usada como revestimento, devido às suas características que proporcionam proteção em superficies metálicas. Neste sentido foi feito um estudo sobre a incorporação de níquel metálico, como dopante na PAni, para medir seu potencial anticorrosivo quando aplicado em uma tinta a óleo e imerso em um ambiente marinho. $\mathrm{O}$ resultado de condutividade elétrica da PAni-ES foi de 52,26 $\mu$ S.cm ${ }^{-1}$ e da PAni-Ni foi de 30,61 $\mu \mathrm{S} . \mathrm{cm}^{-1}$. O respectivo $p \mathrm{H}$ foram ácidos com valores de 2,15 e 5,51. Na absorção óptica notou-se que a PAni-Ni não se transformou em sal de esmeraldina (condutora) e por esse motivo teve uma condutividade menor que a PAni-ES. Em relação à aplicação nas placas de vidro e ferro, os resultados foram satisfatórios, pois a tinta a óleo juntamente com a PAni-Ni mostrou-se ter uma ação de proteção anticorrosiva mais eficiente.
\end{abstract}

\section{INTRODUÇÃO}

As pesquisas sobre os polímeros intrinsecamente condutores (PIC) tiveram início no ano de 1973, porém em 1977 foi observado que em presença de agentes oxidantes (ou agentes redutores) suas características podiam mudar apresentando-se como alternativa vantajosa na elaboração de proteção contra a corrosão.

Em decorrência da corrosão, as superficies metálicas sofrem com a modificação da sua aparência e propriedades específicas. Para resolver este problema estudos demonstram que PIC orgânicos ou sintéticos aplicados em superficies metálicas contribuem para desaceleração deste processo, no qual o mesmo em forma oxidável gera uma camada de filme protetor em metais oxidáveis contra a ferrugem (oxidação) sendo uma das propriedades bastante promissoras destes polímeros (Almeida, 2008).

$\mathrm{Na}$ seleção de polímeros categoricamente condutores, um critério importante a ser observado é a facilidade com que o sistema pode ser oxidado ou reduzido. Isto leva a preferência por polímeros com insaturações conjugadas, que possuam baixo potencial de oxidação. Para formar um íon polimérico, os elétrons de caráter $\pi$ podem ser retirados ou adicionados, sem a destruição das ligações necessárias para estabilidade da macromolécula. Por esse motivo entre os polímeros condutores destaca-se a Polianilina (PAni) por sua estabilidade química em condições ambientais, processabilidade, facilidade de polimerização e dopagem, baixo custo e suas propriedades únicas. Ela forma uma recente 


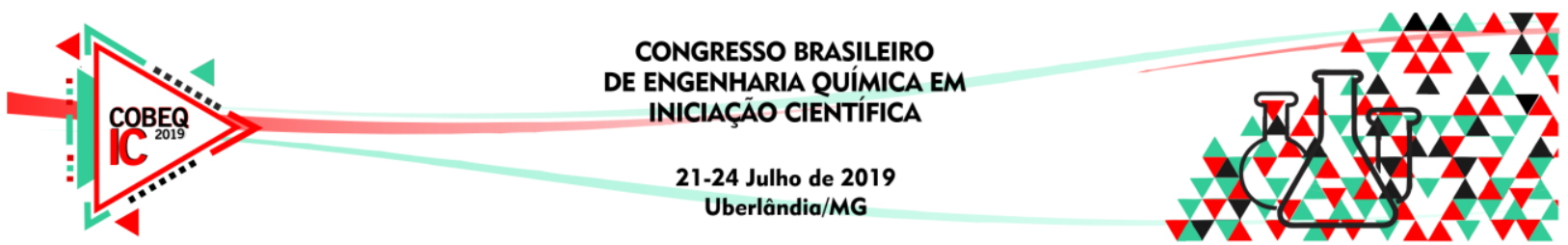

classe de polímeros condutores porque pode ser dopada por protonação, ou seja, sem ter alteração no número de elétrons agregados a cadeia polimérica (Almeida, 2008).

Nesse sentido, a PAni, para se adquirir o polímero na forma dopada, os nitrogênios imina destas espécies podem estar totais ou parcialmente protonados. Na situação de esmeraldina-ES a dopagem química da polianilina é feita por protonação em solução aquosa, ocasionando um aumento na condutividade de cerca de 10 ordens de grandeza ( $\delta=1-5{\mathrm{~S} . \mathrm{cm}^{-1}}$ pastilha prensada) em relação a polianilina não dopada. O estado de oxidação da esmeraldina é a forma na qual, após a dopagem, a PAni alcança os maiores valores de condutividade. $\mathrm{O}$ grau de protonação da base depende do grau de oxidação que o polímero foi sintetizado, e do $p \mathrm{H}$ da solução dopante (Senisse, 2009).

O objetivo do presente trabalho é sintetizar PAni dopada com íon de Ni afim de medir seu potencial anticorrosivo quando manipulado em uma tinta a óleo, e feito seu monitoramento em uma simulação de solução agressiva e ambiente marinho.

\section{METODOLOGIA}

\section{1- Materiais e Síntese}

As soluções de $\mathrm{HCl}$ (Ácido Clorídrico) e $\mathrm{NaOH}$ (Hidróxido de Sódio) à 1 mol.L $\mathrm{L}^{-1}$ foram preparadas no Laboratório de Química Geral no bloco M do Centro Universitário de Patos de Minas - UNIPAM. Para a síntese da PAni-ES dissolveram-se em um balão de fundo redondo $4 \mathrm{~mL}$ de anilina - PA NEON em $40 \mathrm{~mL}$ de $\mathrm{HCl} 1$ mol.L $\mathrm{L}^{-1}$. A mistura foi colocada em banho de gelo e sob agitação magnética.

Separadamente dissolveram-se $2 \mathrm{~g}$ de $\left(\mathrm{NH}_{4}\right)_{2} \mathrm{~S}_{2} \mathrm{O}_{8}$ (Persulfato de Amônio) obtido de Anidrol com $150 \mathrm{~mL}$ de $\mathrm{HCl} 1 \mathrm{molL}^{-1}$ e verteu-se dentro de um funil de separação. Adicionou-se então lenta e cuidadosamente essa solução no balão contendo a anilina. Manteve-se o sistema em agitação por aproximadamente duas horas onde várias mudanças de coloração foram apresentadas.

Após duas horas do sistema em agitação filtrou-se o conteúdo em um Funil de Buchner sob vácuo, lavando com solução de $\mathrm{HCl} 1$ mol.L $\mathrm{L}^{-1}$, resultando em um pó de coloração bem escura e que foi levado para o dessecador.

O resíduo foi monitorado até massa constante e a partir disso foi pesado, armazenado em frasco âmbar. Para a verificação da solubilidade do polímero retirou-se todo o conteúdo restante do papel filtro e lavou-se com solução de (N,N- Dimetilformamida ou DMF Dinamica). A coloração verde indica que é sal de esmeraldina e uma coloração diferente da mesma significa que necessita de redopagem, tendo formado por exemplo a base de esmeraldina.

O teste foi positivo para base de esmeraldina, desta forma, todo o polímero foi redissolvido em aproximadamente $75 \mathrm{~mL}$ de $\mathrm{HCl}$ deixando em agitação por 24 horas, sendo filtrado a vácuo e levado ao dessecador para o mesmo processo de secagem.

Para a incorporação do íon metálico à síntese utilizou-se cerca de $15 \mathrm{~g} \mathrm{NiSO}_{4}$ (sulfato de Níquel - Dinamica) com $250 \mathrm{~mL}$ de $\mathrm{H}_{2} \mathrm{O}$. Pegou-se então aproximadamente $1 \mathrm{~g}$ do polímero e $20 \mathrm{~mL}$ da solução de Sulfato de níquel deixando sob agitação magnética 24 horas, filtrando a vácuo e lavando com acetona. Levou-se à estufa $60^{\circ} \mathrm{C}$ e dessecador até massa constante.

\section{2 - Caracterização do Polímero}




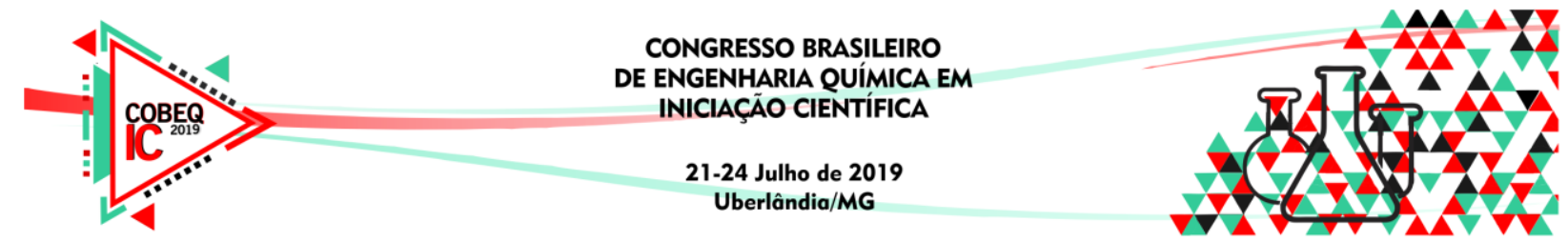

Foi dissolvido cerca de $0,01 \mathrm{~g}$ de cada polímero (com e sem $\mathrm{Ni}$ ) em $20 \mathrm{~mL}$ de dimetilformamida-DMF e realizados os testes de $p \mathrm{H}$, condutividade e absorção óptica. $\mathrm{O}$ teste de $p \mathrm{H}$ foi realizado no $p$ Hmetro Micronal 8474 após a calibração do aparelho com soluções tampão. A condutividade foi medida através do Condutivímetro mCA150 MS Tecnopon instrumentação previamente calibrado com soluções próprias. A absorção óptica foi realizada através do aparelho Espectrofotômetro Genesys 10uv com cubetas para as soluções, usando a solução com íon, sem íon e somente o solvente; onde cada leitura dos valores de absorção foram adicionados a um gráfico.

\section{3 - Aplicação}

O polímero foi aplicado em uma tinta para evitar a corrosão de superfícies metálicas. Adquiriu-se então a tinta à óleo da marca (Brasilux / Brasilar preta) e adicionou-se uma parcela de polímero com íon, uma sem íon (solubilizados em $25 \mathrm{~mL}$ de DMF) e somente a tinta para comparar resultados. Experimentaram-se concentrações diferentes, como mostra na tabela a seguir:

Tabela 1 - Volume PAni/ Tinta

\begin{tabular}{|c|c|c|}
\hline PAni-ES $(\mathrm{mL})$ & PAni-Ni $(\mathrm{mL})$ & Tinta $(\mathrm{mL})$ \\
\hline 2,5 & 2,5 & 15 \\
\hline 4,5 & 4,5 & 25 \\
\hline 6,5 & 6,5 & 40 \\
\hline
\end{tabular}

Foram feitas essas concentrações e aplicadas em placas de vidro e de metal, logo após a secagem, foram levadas a salmoura indicando água do mar $(35 \mathrm{~g}$ de sal para $1000 \mathrm{~mL}$ de água).

\section{RESULTADOS E DISCUSSÃO}

A Tabela 2 abaixo mostra os resultados de $p \mathrm{H}$ e condutividade elétrica, medidos em solução para o polímero com e sem a dopagem com o íon níquel.

Tabela 2 - Resultados de $p \mathrm{H}$ e condutividade elétrica.

\begin{tabular}{|c|c|c|c|c|}
\hline Testes & PAni-ES & PAni-Ni (I) & PAni-Ni (II) & $\begin{array}{c}\text { Tinta com } \\
\text { PAni-Ni (II) }\end{array}$ \\
\hline $\boldsymbol{p H}$ & 2,15 & 3,95 & 5,51 & - \\
\hline $\begin{array}{c}\text { Condutividade } \\
\text { elétrica }\left(\boldsymbol{\mu S . c \mathbf { c m } ^ { - 1 } )}\right.\end{array}$ & 52,26 & 25,89 & 30,61 & 0,66 \\
\hline
\end{tabular}

Todos os valores de $p \mathrm{H}$ das amostras de PAni-ES e PAni-Ni (I) e (II) apresentaram-se ácidos e, não foram encontrados valores na literatura para comparação. Por ter maior condutividade, o teste de absorção óptica e a aplicação foram usados apenas com a PAni-Ni 


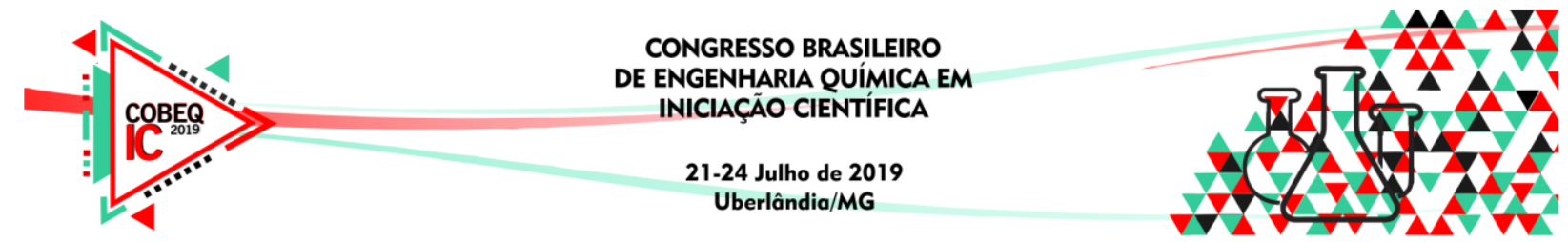

(II). A condutividade elétrica foi estudada em função da incorporação de níquel metálico em relação às PAni-ES, PAni-Ni e a tinta a óleo com PAni-Ni. No trabalho feito por F. Baldissera

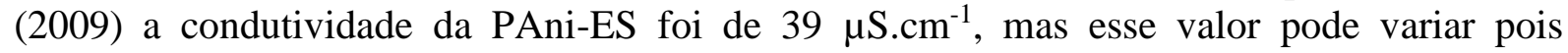
depende das condições de síntese. Nota-se que a condutividade da PAni-Ni é menor que a PAni-ES, e era de se esperar que a condutividade fosse maior pela presença do Ni. Esse valor menor pode ser justificado pelo fato de que, na redopagem, a PAni-Ni pode ter se transformado em base esmeraldina (isolante). Segundo Harun Mh (2002) a quantidade de níquel provoca um baixo valor de condutividade. Isso sugere que os íons metálicos atrapalham o caminho condutor da PAni quando esta se encontra no estado condutor ES, dificultando o processo de condução dos portadores de cargas. Pode-se ainda interpretar essa variação na condutividade com a hipótese de que as partículas tenham atuado como impurezas em relação à PAni. A condutividade da tinta com a PAni-Ni já era de se esperar um valor baixo, devido às propriedades do óleo que são isolantes.

A espectroscopia de absorção óptica da PAni-ES e PAni-Ni foi realizada na faixa de comprimento de onda de 200 a $800 \mathrm{~nm}$. Os espectros, apresentados na Figura 1, apresentam uma banda posicionada no comprimento de onda $265 \mathrm{~nm}$ e logo depois em $280 \mathrm{~nm}$ claramente formam um pico. De acordo com Izume et al. (2009) esta banda é atribuída à transição $\pi-\pi$ e transferência de carga entre anéis benzenóides e quinóides que ocorreu até o comprimento de onda $315 \mathrm{~nm}$.

Figura 1 - Espectros de absorção da PAni-ES e PAni-Ni

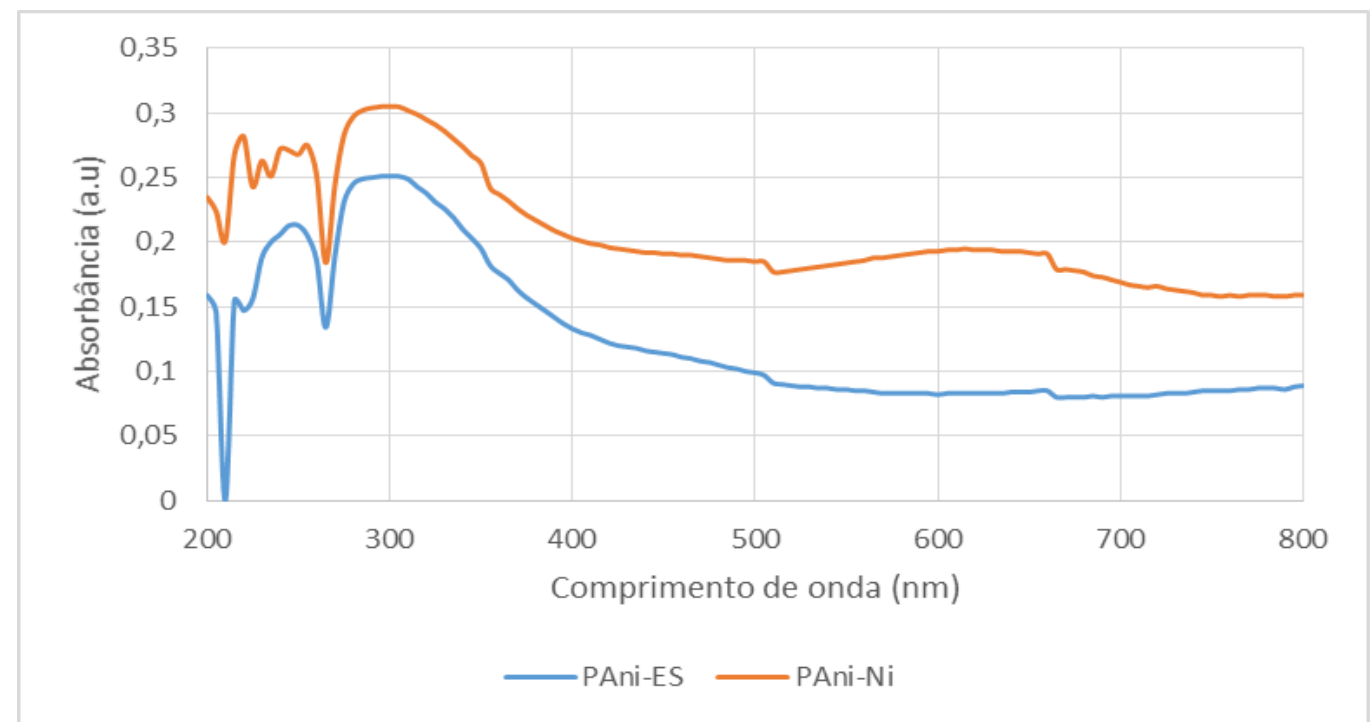

As placas já pintadas e secas foram banhadas na solução de ambiente marinho por 11 dias para que a simulação fosse feita, após esse intervalo as placas foram retiradas para uma análise visual, sendo constatado que as placas que continham apenas a tinta e com PAni-Es sofreram deterioração maior do que as com Pani-Ni.

\section{CONCLUSÃO}

Conforme o objetivo proposto, a partir da síntese da PAni juntamente com íon de níquel, quando manipulado em uma tinta a óleo, pode atuar como proteção anticorrosiva. Os testes realizados mostraram-se satisfatórios durante o tempo que foi monitorada. 


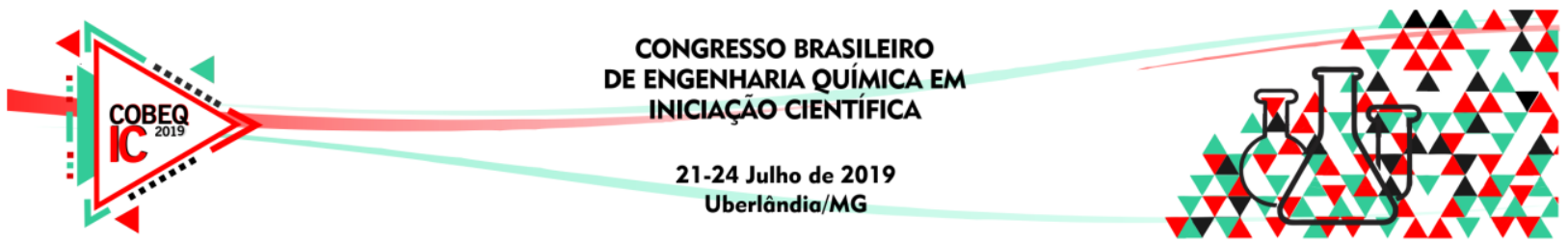

Como monitoramento foi simulado em solução agressiva e ambiente marinho, as áreas litorâneas teriam grande beneficiamento com o uso dessas tintas, já que elas têm proteção anticorrosiva.

No entanto seria necessário realizar mais estudos referentes a esses tipos de aplicação, e poder concluir um monitoramento por um período maior.

\section{REFERÊNCIAS}

ALMEIDA, Álvaro de Mello; FORNARI JR, Celso Carlino Maria. Aplicações tecnológicas da Polianilina - Um polímero condutor - Revista Tecnologia e Tendências - 2003 v. 2, n. 1. Disponivel em:

$<$ http://periodicos.feevale.br/seer/index.php/revistatecnologiaetendencias/article/view/137 9>. Acesso em: 13 junho 2018.

ALMEIDA, Gisela Ferraz. Estudo da proteção à corrosão pelo uso de polímeros condutores -

Instituto de Química. São Paulo, 2008 Disponível em:

<http://www.teses.usp.br/teses/disponiveis/46/46132/tde-04042008-160044/pt-br.php>. Acesso em: 14 junho 2018.

DIAS, Gabriel da Cruz; DE PAULA, Fernando Rogério; MALMONGE, José Antonio ; MALMONGE, Luiz Francisco. Preparação e caracterização do compósito PVDF/Pani com partículas de níquel - Polímeros vol.27 no.spe São Carlos 2017 Epub 16-Jan-2017. Disponivel em: 〈http://dx.doi.org/10.1590/0104-1428.2277>. Acesso em: 13 junho 2018.

MATTOSO, Luiz Henrique C; Centro Nacional de Pesquisa e Desenvolvimento de Instalação Agropecuárias - São Paulo, 1995. Disponível em:

http://quimicanova.sbq.org.br/imagebank/pdf/Vol19No4_388_v19_n4_09.pdf. Acesso em: 16 junho 2018.

SENISSE, Carolina Alves de Lima; BALDISSERA, Alessandra Fiorini; MIRANDA, Karine Leite. Aplicação de Polímeros Condutores na preparação de tintas com poder anti-incrustante para proteção de embarcações e estruturas metálicas - Salão de Iniciação Científica 2009. Disponível em: < http://hdl.handle.net/10183/43011>. Acesso em: 14 junho 2018.

SILVA, Rodrigo Sanchotone.

Binder a base de polianilina para proteção anódica de aço carbono. Disponível em: <http://hdl.handle.net/10183/31388>. Acesso em: 14 junho 2018. 


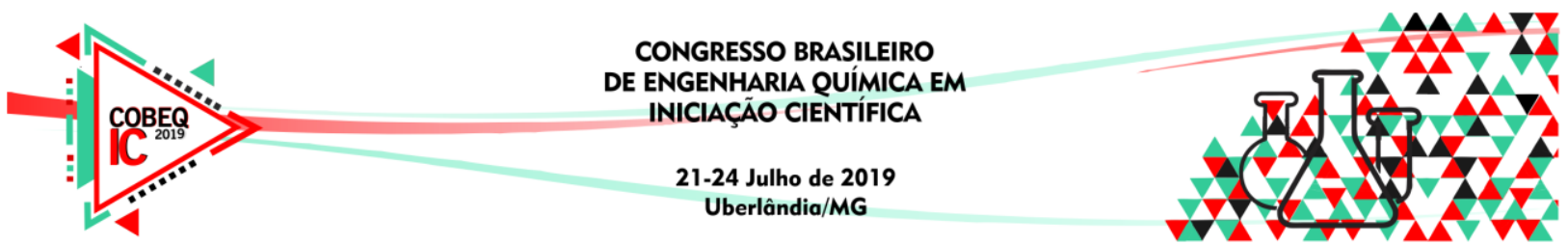

SILVA, Rodrigo S. et al. Filme autosuportado de polianilina desdopada para aplicações anticorrosivas. Polímeros [online]. 2012, vol.22, n.3, pp.288-294. Epub June 21, 2012. ISSN 0104-1428. Disponível em: <http://dx.doi.org/10.1590/S0104-14282012005000039>. Acesso em: 16 junho 2018. 